\section{Generation $Y$ and the clinical clerkship: different teaching modalities in internal medicine}

\author{
Jeffrey Kushinka, Gonzalo Bearman \\ Virginia Commonwealth University \\ School of Medicine, Richmond, Virginia, \\ USA
}

There is currently an important need to incorporate innovative teaching methods into medical school curricula. In response to the predicted physician shortage (on the basis of currently available evidence), the Association of American Medical Colleges (AAMC) has called for a $30 \%$ increase in medical school enrollment. ${ }^{1}$ Yet as class size increases, funding for medical education has often remained flat, meaning that more students need to be taught with the same resources. In addition, the learning preferences of today's medical students (labeled Generation Y, the generation born between 1980 and 1994) may differ from those of previous generations, often preferring more visual and hands-on modes of information acquisition. ${ }^{2}$ Finally, more medical schools have made incorporating learner-centered teaching (as opposed to traditional lectures) a priority. As such, teaching modalities that engage students and deliver key content in a time- and resource-efficient manner are urgently needed.

Team-based learning (TBL) and cardiac simulation training (CST) may meet the stated objectives. TBL is an adult learner-centered teaching strategy that provides the benefits of small-group learning while using a single facilitator. $^{3}$ CST is an instructor-led, small-group experience that teaches the essentials of cardiac auscultation using a high-fidelity cardiopulmonary simulator mannequin. Both TBL and CST are promising techniques that increase student engagement and may prove superior to traditional lectures in transferring knowledge to Generation Y students.

TBL and CST may improve performance in medical school. In a recent study of students in their pre-clinical years, Koles et al. demonstrated that $2^{\text {nd }}$-year medical students scored higher on examination questions that related to content taught in a TBL format as compared to content taught in a traditional lecture format. ${ }^{4}$ They also noted that students who scored in the lowest quartile showed the most improvement on the TBL-taught content, suggesting that TBL may be particularly useful for students who struggle with traditional lecture formats. Thomas and Bowen recently have demonstrated improved performance on writ- ten examination scores among ambulatory medicine clerkship students taught via TBL. ${ }^{5}$ These are among the first studies to assess the impact of TBL on student performance during their clinical years of medical school.

Similarly CST is associated with improved medical student performance when compared to standard bedside teaching. In two studies students taught via CST performed better on both written examinations and clinical skills examinations.$^{6,7}$ CST on a high-fidelity simulator has several advantages compared to traditional bedside teaching. First, it offers exposure to multiple cardiac conditions that students may not encounter during a typical clerkship. This is particularly important as the incidence of certain conditions, e.g. mitral stenosis due to rheumatic fever, has decreased substantially. Second, CST allows multiple learners to practice simultaneously through the use of technological aids and allows one expert facilitator to train multiple students. This feature is of particular importance with looming increases in class sizes and stagnant or shrinking budgets. Third, CST can in theory provide unlimited practice to students to improve their skills. Valuable practice time is frequently unavailable in a busy office or hospital setting, where there is an ever-increasing emphasis on seeing patients as quickly as possible.

At our own medical school, both TBL and CST sessions given during the third-year internal medicine clerkship were considered significantly more engaging and more clinically useful compared to traditional lectures (unpublished data). Even with consideration of the recent study by Thomas and Bowen, very little is known about the impact of TBL on clinical performance. As with our own data, initial studies on relatively new techniques such as TBL frequently assess student attitudes and preferences rather than performance indicators (e.g. test scores, clinical evaluations by attending physicians, etc.). ${ }^{8}$ As more clerkships utilize non-traditional teaching modalities such as TBL, it will be important to study whether such modalities can improve clinical performance.

In summary, medical educators are facing a potential collision of competing interests: increased class size, limited educational resources, a mandate to develop more engaging and learner-centered curricula, and a generation of students unlikely to be satisfied with traditional lectures. It is increasingly important that medical educators implement innovative techniques to meet the goals of Generation Y medical students while efficiently using limited educational resources. TBL and CST are two such techniques that seem
Correspondence: Jeffrey Kushinka,

Virginia Commonwealth University Schoo of Medicine, Richmond, Virginia, USA.

Tel. +1.804 8281931 - Fax +1.804 8284926 .

E-mail: jkushinka@mcvh-vcu.edu

Received for publication: 21 October 2010. Accepted for publication: 11 July 2011.

This work is licensed under a Creative Commons Attribution NonCommercial 3.0 License (CC BYNC 3.0).

(C)Copyright J. Kushinka and G. Bearman et al., 2011 Licensee PAGEPress, Italy

Medical Education Development 2011; 1:e7 doi:10.4081/med.2011.e7

well-placed to satisfy these competing requirements. We call for robust, large studies to evaluate the impact of these and similar techniques upon student performance.

\section{References}

1. AAMC. Medical school enrollment plans: analysis of the 2007 AAMC survey. Available from: www.aamc.org.

2. Weiler A. Information-seeking behavior in Generation Y students motivation, critical thinking, and learning theory. Journal of Academic Librarianship. 2005;31:46-53.

3. Michaelson LK. Getting started with teambased learning. In Team-Based Learning: A Transformative Use of Small Groups in College Teaching. Michaelson LK, Knight AB, Fink LD (eds.). Sterling, VA: Stylus; 2004.

4. Koles PG, Stolfi A, Borges NJ, et al. The impact of team-based learning on medical students' academic performance. Acad Med 2010;85:1739-45.

5. Thomas PA, Bowen CW. A controlled trial of team-based learning in an ambulatory medicine clerkship for medical students. Teach Learn Med 2011;23:31-6.

6. Okuda Y, Bryson EO, DeMaria Jr. S, et al. The utility of simulation in medical education: what is the evidence? Mt. Sinai J Med 2009;76:330-43.

7. Kern DH, Mainous AG 3rd, Carey M, Beddingfield A. Simulation-based teaching to improve cardiovascular exam skills performance among third-year medical students. Teach Learn Med 2011;23:15-20.

8. Parmelle DX, DeStephen D, Borges NJ. Medical students' attitudes about teambased learning in a pre-clinical curriculum. Med Ed Online 2009;14:1. 